\title{
RESEARCH
}

Open Access

\section{Extent, nature and consequences of performing outside scope of training in global health}

\author{
Ashti Doobay-Persaud ${ }^{1,2^{*}}$ (D), Jessica Evert ${ }^{3,4}$, Matthew DeCamp ${ }^{5}$, Charlesnika T. Evans ${ }^{6}$, Kathryn H. Jacobsen ${ }^{7}$,
} Natalie E. Sheneman², Joshua L. Goldstein ${ }^{8}$ and Brett D. Nelson ${ }^{9,10}$

\begin{abstract}
Background: Globalization has made it possible for global health professionals and trainees to participate in short-term training and professional experiences in a variety of clinical- and non-clinical activities across borders. Consequently, greater numbers of healthcare professionals and trainees from high-income countries (HICs) are working or volunteering abroad and participating in short-term experiences in low- and middleincome countries (LMICS). How effective these activities are in advancing global health and in addressing the crisis of human resources for health remains controversial. What is known, however, is that during these short-term experiences in global health (STEGH), health professionals and those in training often face substantive ethical challenges. A common dilemma described is that of acting outside of one's scope of training. However, the frequency, nature, circumstances, and consequences of performing outside scope of training (POST) have not been wellexplored or quantified.
\end{abstract}

Methods: The authors conducted an online survey of HIC health professionals and trainees working or volunteering in LMICs about their experiences with POST, within the last 5 years.

Results: A total of 223 survey responses were included in the final analysis. Half (49\%) of respondents reported having been asked to perform outside their scope of training; of these, $61 \%$ reported POST. Trainees were nearly twice as likely as licensed professionals to report POST. Common reasons cited for POST were a mismatch of skills with host expectations, suboptimal supervision at host sites, inadequate preparation to decline POST, a perceived lack of alternative options and emergency situations. Many of the respondents who reported POST expressed moral distress that persisted over time.

Conclusions: Given that POST is ethically problematic and legally impermissible, the high rates of being asked, and deciding to do so, were notable. Based on these findings, the authors suggest that additional efforts are needed to reduce the incidence of POST during STEGH, including pre-departure training to navigate dilemmas concerning POST, clear communication regarding expectations, and greater attention to the moral distress experienced by those contending with POST.

Keywords: Global health, Medical education, Ethics, Scope of training, Scope of practice, Professionalism

\footnotetext{
* Correspondence: a-doobay-persaud@northwestern.edu

${ }^{1}$ Division of Hospital Medicine, Departments of Medicine and Medical

Education, Feinberg School of Medicine, Northwestern University, 51 E Huron

St, Chicago, IL 60611, USA

${ }^{2}$ Institute for Global Health, Feinberg School of Medicine, Northwestern

University, 645 N Michigan Ave, Suite 1058, Chicago, IL 60611, USA

Full list of author information is available at the end of the article
}

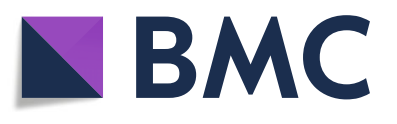

(c) The Author(s). 2019 Open Access This article is distributed under the terms of the Creative Commons Attribution 4.0 International License (http://creativecommons.org/licenses/by/4.0/), which permits unrestricted use, distribution, and

reproduction in any medium, provided you give appropriate credit to the original author(s) and the source, provide a link to the Creative Commons license, and indicate if changes were made. The Creative Commons Public Domain Dedication waiver (http://creativecommons.org/publicdomain/zero/1.0/) applies to the data made available in this article, unless otherwise stated. 


\section{Background}

Alongside the increasing globalization of the world's modern economies, cultures, and populations there has been a parallel globalization in healthcare, with countless clinicians and organizations working across international borders. Indeed, every year, thousands of healthcare professionals and medical trainees engage in short-term experiences in global health (STEGH) [1-7]. Ranging in duration from 1 week to a few months, STEGH typically involve health professionals from high-income countries (HICs) traveling to low- and middle-income countries (LMICs) for educational, training, capacity-building, or research purposes.

Ethical and best practice guidelines emphasize that such programs should primarily and sustainably benefit the local community [3, 7-12]. This emphasis arose out of the recognition that STEGH can burden communities, fail to meet expectations, and even cause unintentional harms $[3,7,9,12-20]$. One of the many ethical challenges associated with STEGH arises when visiting clinicians and trainees are faced with opportunities or requests to perform outside the scope of their training [3, 8, 21-28]. Locally licensed clinicians working in LMICs often have a broader scope of practice than clinicians who work in HICs, where specialty practice is common. Existing literature around STEGH provides qualitative and case-based evidence that performing outside scope of training (POST) can be a particular challenge for HIC professionals and trainees operating in unfamiliar clinical and cultural environments and working under resource constraints [17, 21, 23, 27, 29-31]. In addition, there is growing evidence that pre-health students seek out the opportunity to practice beyond their scope of training due to curiosity, eagerness for clinical exposure, and belief that it will improve their likelihood of gaining admission to their desired schools. Despite ethical guidelines recommending against POST, exigent circumstances such as humanitarian emergencies, critical personnel shortages, or the absence of referral options may seem to require some level of POST. Even then, POST requires careful consideration of context, competence, comfort, and circumstances [3, 7, 8, 22, 26, 32-34]. In practice, POST can reveal the tension between the duty to provide care and the imperative to do no harm $[8,26,32,35]$. Frameworks to aid in ethical decision-making around scope of practice have been proposed, but prior research has focused on qualitative case studies of trainee groups or professionals working in humanitarian settings $[3,5,7,9,16,24,28,32,35-38]$. Whether existing frameworks apply to health professionals more broadly or to less acute situations encountered during STEGH remains unknown.

The goals of this study were to clarify the circumstances under which health professionals and trainees face requests to perform outside their training during STEGH, and to explore the perceived impact of POST on practitioners.

\section{Methods \\ Survey design}

A research team composed of experienced clinical and global health faculty designed a survey instrument including 39 closed- and open-response questions about demographics, STEGH during the past 5 years, and POST (Additional file 1). STEGH locations were classified based on the World Health Organization definitions for health system levels [39]. Global health faculty and trainees at Northwestern University Feinberg School of Medicine, Harvard Medical School, and the University of California, San Francisco School of Medicine pilot-tested the survey for content validity. The draft questionnaire was revised based on their feedback. The survey instrument and an abridged report of limited findings have been previously described elsewhere [40].

The study protocol was approved by the institutional review board of Northwestern University (Protocol STU00205018).

\section{Recruitment and data collection}

Data were collected online between April and July 2017. Survey participants were recruited via convenience sampling at global health-related academic conferences, within professional networks, and via email listservs, including the Consortium of Universities for Global Health, American Academy of Pediatrics, American Academy of Family Practitioners, Global Emergency Medicine Academy, and Society for Hospital Medicine. Recipients could forward the link to the online survey, resulting in additional participants recruited through snowball sampling. Responses were collected via Qualtrics (Provo, UT, USA). Respondents were allowed to proceed with the survey if they self-identified as being at least 18 years of age and having participated in STEGH in an LMIC or another resource-constrained setting within the preceding 5 years.

\section{Quantitative data analysis}

Univariate statistics including means, medians, frequencies, percentages, and standard deviations were used to describe quantitative survey responses. A variable for "returner status" was developed, grouping "non-returners" who never returned to the same STEGH site, "returners" who went to the same STEGH site 2-5 times, and "frequent returners" who went to the same STEGH site six or more times in the preceding 5 years. Bivariate analyses using chi-square statistics were used to examine associations between demographic and POST variables. All quantitative analyses were conducted using SAS, version 9.4 (SAS Institute, Cary, NC, USA). 


\section{Qualitative data analysis}

An emergent thematic content analysis approach was used to code qualitative responses [37]. First, two researchers (JE, MD) reviewed more than half of the openended responses line-by-line and developed a set of preliminary codes. Because many of the responses included emotional overtones, an emotive style of coding was pursued [41]. Related sections of text were grouped into categories based on the preliminary codes and emergent patterns in the data. After two iterations of this process, a codebook was developed. Next, coding was undertaken independently by two other researchers (ADP, KHJ) who reviewed the free text responses line-by-line and assigned codes from the final codebook. To help ensure inter-coder reliability, the two researchers discussed and resolved coding discrepancies. Coding disagreements were resolved by a third researcher (JE) through negotiated consensus. To ensure accuracy, the original coders then reviewed and confirmed the assigned codes for half of the line-by-line transcripts. Reflexivity techniques, such as being open and transparent about the researchers' own views, were used through the coding process. The coders' own perspectives as individuals with expertise in global health education and/or ethics related to STEGH, and hence familiarity with existing guidelines, are important to acknowledge.

\section{Results}

A total of 262 survey responses were received. The final analysis included the 223 respondents who answered at least one question about POST (Fig. 1). Respondents spent a median of 28 days participating in STEGH in the preceding year and 30 days annually during the preceding 5 years. Many respondents had spent several months on STEGH, so the mean (standard deviation) was much higher: 73 days (105) in the past year and 80 days (102) annually over the past 5 years. More than $80 \%$ of the respondents had made several visits to the same site for STEGH. The typical respondent was in the medical field (82\%), had trained in North America (84\%), was a licensed health professional (66\%), and had an intentional clinical focus $(86 \%)$ during STEGH in LMIC settings (Table 1).

\section{Requests to perform outside scope of training}

Respondents perceived that requests to perform outside their scope of training occurred often during STEGH. Nearly half $(49 \%)$ of survey respondents reported that they were asked to perform beyond their scope during STEGH in the preceding five years (Table 2). Of these, $37 \%$ were asked 1-3 times, $30 \%$ were asked 4-10 times, and $33 \%$ more than 10 times. Nearly every demographic group that participated in the study reported a high rate of being asked to perform outside scope of training

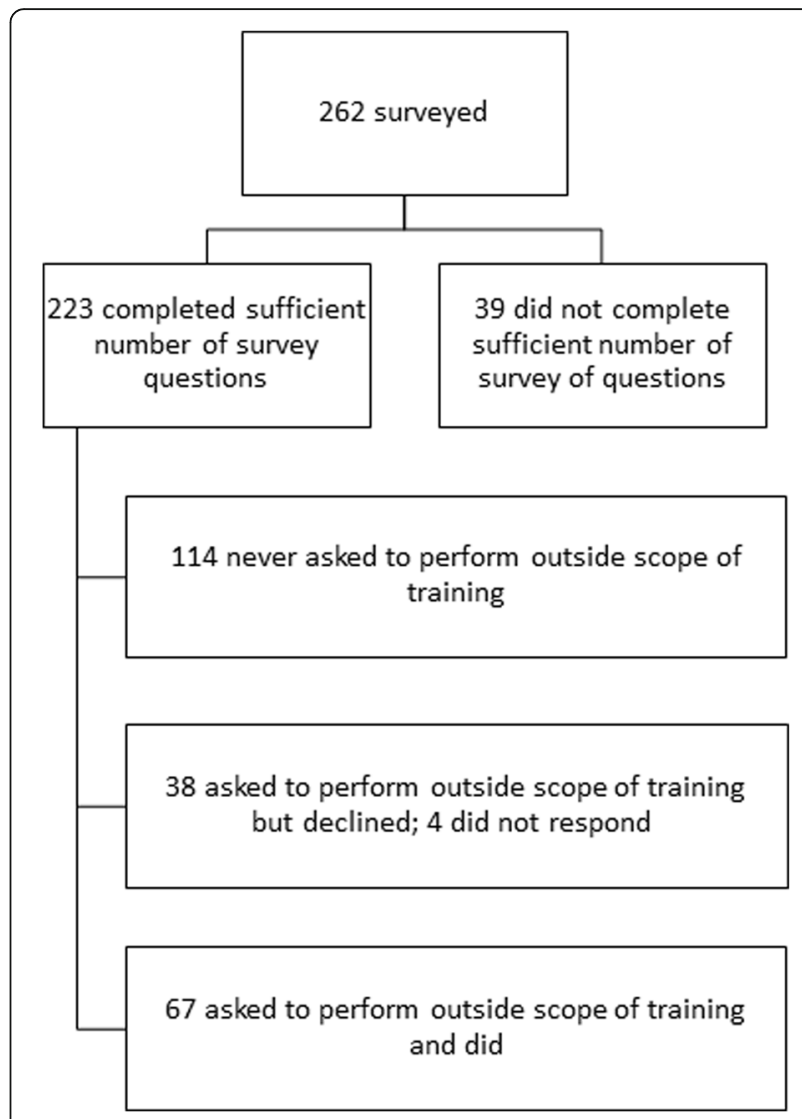

Fig. 1 Study Participant Inclusion Chart

(Table 3), but respondents identified some variation by setting. For example:

"[It] largely depends on the setting. A large academic center in an LMIC with multiple international collaborations, for example, may be better equipped to manage and assign duties to rotating medical students, residents, and faculty without causing an ethical dilemma. However, a site that is severely understaffed with few international connections may ask more of visitors... Out of the various experiences I have had abroad, [being asked to perform outside scope of training] was most apparent at a small, rural clinic in [Country A]. During my time at a large hospital in [Country B], however, I rarely had the problem arise." (Allopathic medical student)

\section{Engaging in POST}

Of those asked to perform outside their training, 61\% $(67 / 109)-30 \%$ of all respondents-reported engaging in POST. Forty-two percent of this subset indicated doing so $1-3$ times over the prior 5 years, 30\% reported $4-10$ times, and 28\% more than 10 times (Table 2). Medical students (100\%) and residents and fellows (81\%) 
Table 1 Survey Respondent Demographics $(N=223)$

\begin{tabular}{|c|c|c|c|}
\hline \multicolumn{2}{|l|}{ Demographic Description } & \multirow{2}{*}{$\frac{n}{183}$} & \multirow{2}{*}{$\frac{\%}{82.1}$} \\
\hline Degree $^{a}$ & MD/DO & & \\
\hline & RN & 8 & 3.6 \\
\hline & $\begin{array}{l}\text { Physician assistant/nurse } \\
\text { practitioner }\end{array}$ & 8 & 3.6 \\
\hline & Other & 24 & 10.8 \\
\hline \multirow[t]{2}{*}{ Medical Discipline ${ }^{a}$} & Internal or Family Medicine & 62 & 27.8 \\
\hline & Other specialties & 161 & 72.2 \\
\hline \multirow[t]{7}{*}{ Professional Status ${ }^{a}$} & Licensed practitioner & 146 & 65.5 \\
\hline & Trainee & 65 & 29.1 \\
\hline & Fellow & 15 & 6.7 \\
\hline & Resident & 34 & 15.2 \\
\hline & Medical student & 15 & 6.7 \\
\hline & Other clinical field & 1 & 0.4 \\
\hline & Other & 12 & 5.4 \\
\hline \multirow[t]{8}{*}{ Training Region } & North America & 134 & 84.3 \\
\hline & Other & 25 & 15.7 \\
\hline & Latin American/Caribbean & 7 & 4.4 \\
\hline & South Asia & 5 & 3.1 \\
\hline & Europe and Central Asia & 4 & 2.5 \\
\hline & Sub-Saharan Africa & 4 & 2.5 \\
\hline & Middle East and North Africa & 1 & 0.6 \\
\hline & Unknown & 64 & - \\
\hline \multirow[t]{2}{*}{ STEGH Professional Role } & Clinical & 191 & 85.7 \\
\hline & Non-clinical & 32 & 14.4 \\
\hline \multirow[t]{7}{*}{ STEGH World Bank Region ${ }^{a}$} & Sub-Saharan Africa & 109 & 48.9 \\
\hline & Latin American and Caribbean & 107 & 48.0 \\
\hline & South Asia & 44 & 19.7 \\
\hline & East Asia and Pacific & 25 & 11.2 \\
\hline & North America & 17 & 7.5 \\
\hline & Middle East and North Africa & 12 & 5.4 \\
\hline & Europe and Central Asia & 7 & 3.1 \\
\hline \multirow[t]{5}{*}{ STEGH Location ${ }^{a}$} & Urban & 135 & 60.5 \\
\hline & Rural & 115 & 51.6 \\
\hline & District/village & 91 & 40.8 \\
\hline & Peri-urban & 41 & 18.4 \\
\hline & Other & 4 & 1.8 \\
\hline \multirow[t]{5}{*}{ STEGH Organization Type ${ }^{a}$} & NGOs and other non-profits & 143 & 64.1 \\
\hline & University & 99 & 44.4 \\
\hline & Governmental & 58 & 26.0 \\
\hline & $\begin{array}{l}\text { International bilateral, } \\
\text { multilateral, and health } \\
\text { care foundations }\end{array}$ & 28 & 12.6 \\
\hline & Other & 13 & 5.8 \\
\hline STEGH Care Setting ${ }^{\mathrm{a}}$ & $\begin{array}{l}\text { Specialty hospital or } \\
\text { national referral center }\end{array}$ & 94 & 42.2 \\
\hline
\end{tabular}

Table 1 Survey Respondent Demographics ( $N=223)$

(Continued)

\begin{tabular}{|c|c|c|c|}
\hline Demographic Description & & $n$ & $\%$ \\
\hline & Primary level or district hospital & 93 & 41.7 \\
\hline & $\begin{array}{l}\text { Community health workers } \\
\text { in home or village setting }\end{array}$ & 73 & 32.7 \\
\hline & Primary care clinic & 68 & 30.5 \\
\hline & Health center or dispensary & 37 & 16.6 \\
\hline & Other & 23 & 10.3 \\
\hline \multirow[t]{4}{*}{ Returned to STEGH location } & Non-returner (1 trip) & 19 & 8.5 \\
\hline & Returner (2-5 trips) & 116 & 52.0 \\
\hline & $\begin{array}{l}\text { Frequent returner ( } 6 \text { or } \\
\text { more trips) }\end{array}$ & 63 & 28.3 \\
\hline & No response & 25 & 11.2 \\
\hline
\end{tabular}

reported higher rates of POST than licensed physicians (51\%) $(p=0.001)$ (Table 3$)$. The most frequently performed POST procedures included basic ultrasound (15\%), fracture management (12\%), wound care and suturing of lacerations (12\%), endotracheal intubation (9\%), vaginal delivery $(9 \%)$, and neonatal resuscitation (9\%). Of the 67 respondents who did engage in POST, $33 \%$ indicated that it was "very" or "completely" likely that they would make the same decision in similar situations; however, only $15 \%$ felt "very" prepared to manage requests to perform outside their scope..

\section{Perceptions about appropriateness of and reasons for POST}

Sixty percent $(136 / 223)$ of respondents reported that it is or could be appropriate for HIC health professionals participating in STEGH to perform beyond their scope of training in some situations (Table 2). Licensed practitioners $(69 \%)$ were more likely than others $(49 \%)$ to believe that POST is or could be appropriate $(p=0.004)$ (Table 3). When offered a list of potential factors that might contribute to POST, respondents identified several common factors, including mismatch between hosts' expectations and visiting health professionals' training (37\%), a suboptimal level of supervision at the host site (21\%), inadequate preparation to decline POST (19\%), and perception of an inadequate level of available staff, equipment, or resources (13\%) (Table 2).

Those who believed POST was appropriate often cited emergency situations and a perceived lack of alternative options.

"When there are no alternative providers and the situation clinically requires it, it may be the only option available to a patient." (Licensed MD, Internal Medicine). 
Table 2 Perceptions, Prevalence, and Reasons Related to POST by Health Professionals During STEGH

\begin{tabular}{|c|c|c|c|}
\hline Survey Question & Response & $\mathrm{n} / \mathrm{N}$ & $\%$ \\
\hline \multirow[t]{5}{*}{ How often do HIC professionals perform clinically beyond their scope of training? } & Always & $4 / 223$ & 1.8 \\
\hline & Frequently & $81 / 223$ & 36.3 \\
\hline & Sometimes & $75 / 223$ & 33.6 \\
\hline & Infrequently & $48 / 223$ & 21.5 \\
\hline & Never & $15 / 223$ & 6.7 \\
\hline \multirow[t]{4}{*}{ Do you believe it is appropriate for HIC-trained clinicians to perform beyond their scope of training? } & Yes & $13 / 223$ & 5.8 \\
\hline & No & $65 / 223$ & 29.2 \\
\hline & It depends & $123 / 223$ & 55.2 \\
\hline & No response & $22 / 223$ & 9.5 \\
\hline Were you ever asked to perform clinical activities beyond your scope of training? & Yes & $109 / 223$ & 48.9 \\
\hline \multirow[t]{4}{*}{ If yes, number of times: } & $1-3$ & $39 / 105$ & 37.1 \\
\hline & $4-10$ & $31 / 105$ & 29.5 \\
\hline & $>10$ & $35 / 105$ & 33.3 \\
\hline & No response & $4 / 109$ & 3.7 \\
\hline Did you ever perform clinical activities beyond your scope of training? & Yes & $67 / 109$ & 61.4 \\
\hline \multirow[t]{4}{*}{ If yes, number of times: } & $1-3$ & $27 / 64$ & 42.2 \\
\hline & $4-10$ & $19 / 64$ & 29.7 \\
\hline & $>10$ & $18 / 64$ & 28.1 \\
\hline & No response & $3 / 67$ & 4.5 \\
\hline \multicolumn{4}{|c|}{$\begin{array}{l}\text { Why do you feel you were in a situation or situations in which you practiced clinically beyond your scope of training? (May select more than one } \\
\text { answer.) }\end{array}$} \\
\hline My training did not match my host's expectations & & $25 / 67$ & 37.3 \\
\hline I had an inadequate level of supervision in-country & & $14 / 67$ & 20.9 \\
\hline I was inadequately prepared to decline practicing beyond my scope of training & & $13 / 67$ & 19.4 \\
\hline I perceived an inadequate level of available staff, equipment, or resources & & $9 / 67$ & 13.4 \\
\hline I overestimated my own capabilities & & $5 / 67$ & 7.5 \\
\hline I wanted to be able to perform a procedure/technique I was not very familiar with & & $5 / 67$ & 7.5 \\
\hline I did not seek adequate assistance when I needed it & & $1 / 67$ & 1.5 \\
\hline Other & & $13 / 67$ & 19.4 \\
\hline
\end{tabular}

"For elective cases without imminent danger, clinicians should not practice beyond their scope. However, in emergencies, there may be no other alternative. This constitutes a more challenging ethical scenario." (Resident MD, General Surgery).

"Sometimes there are situations that cannot be controlled. If someone is near death on the side of a road, for example, we would not blame a layperson for attempting to help." (Allopathic medical student).

A minority of survey respondents commented that each situation required a consideration of risks and benefits, as well as local capacity.

"Risks and benefits of providing care beyond the scope of training needs to be well accounted for. If there are other providers who are appropriately trained to provide that care, then HIC-trained clinicians should not go beyond their level of training to offer a certain care. However, if the alternative to offering this care is a high risk of an adverse health event, then I believe it is appropriate for any clinician to do their best in caring for patients as needed." (Resident MD, Internal Medicine).

Some respondents provided reflections about the challenges their peers encounter when managing care in unfamiliar settings, observing that visiting clinicians often have a limited understanding of the cultural context, the health system, and available resources.

"HIC-trained clinicians often underestimate the capacity and availability of physicians in LMIC 
Table 3 Bivariate Analysis of Survey Responses About POST During STEGH

\begin{tabular}{|c|c|c|c|c|}
\hline \multicolumn{2}{|l|}{ Category } & \multirow{2}{*}{$\begin{array}{l}\text { Asked to Perform Outside } \\
\text { Scope of Training } \\
\%(n / N)\end{array}$} & \multirow{2}{*}{$\begin{array}{l}\text { Did Perform Outside } \\
\text { Scope of Training } \\
\%(n / N) \\
54.3(57 / 105)\end{array}$} & \multirow{2}{*}{$\begin{array}{l}\text { Believes it is or could be } \\
\text { appropriate to Perform } \\
\text { Outside Scope of } \\
\text { Training\% }(n / N) \\
61.0(136 / 223)\end{array}$} \\
\hline Total & & & & \\
\hline \multirow[t]{2}{*}{ Degree } & MD/DO & $48.1(88 / 183)$ & $60.0(51 / 85)$ & $62.8(115 / 183)$ \\
\hline & Others & $52.5(21 / 40)$ & $80.0(16 / 20)$ & $52.5(21 / 40)$ \\
\hline \multirow[t]{2}{*}{ Medical Discipline } & Internal or Family Medicine & $45.2(28 / 62)$ & $59.2(16 / 27)$ & $62.9(39 / 62)$ \\
\hline & Other Specialties & $50.3(81 / 161)$ & $65.4(51 / 78)$ & $60.3(97 / 161)$ \\
\hline \multirow[t]{4}{*}{ Professional Status } & Licensed practitioner (MD/DO) & $44.7(59 / 132)$ & $50.9(29 / 57)$ & $68.9(91 / 132)$ \\
\hline & Resident/Fellow & $55.1(27 / 49)$ & $80.8(21 / 26)$ & $49.0(24 / 49)$ \\
\hline & Medical student & $66.7(10 / 15)$ & $100.0(10 / 10)$ & $53.3(8 / 15)$ \\
\hline & Other & $48.2(13 / 27)$ & $58.3(7 / 12)$ & $48.2(13 / 27)$ \\
\hline \multirow[t]{2}{*}{ STEGH Professional Role } & Clinical & $52.9(101 / 191)$ & $63.9(62 / 97)$ & $64.9(124 / 191)$ \\
\hline & Non-clinical & $25.0(8 / 32)$ & $62.5(5 / 8)$ & $37.5(12 / 32)$ \\
\hline \multirow[t]{4}{*}{ STEGH Location } & Urban & $42.2(57 / 135)$ & $59.7(34 / 57)$ & $65.2(88 / 135)$ \\
\hline & Rural & $45.2(52 / 115)$ & $65.4(34 / 52)$ & $73.0(84 / 115)$ \\
\hline & District/Village & $46.2(42 / 91)$ & $59.5(25 / 42)$ & $67.0(61 / 91)$ \\
\hline & Periurban & $43.9(18 / 41)$ & $61.1(11 / 18)$ & $53.7(22 / 41)$ \\
\hline \multirow[t]{6}{*}{ STEGH Organization Type } & NGO or non-profit & $45.5(65 / 143)$ & $63.1(41 / 65)$ & $69.9(100 / 143)$ \\
\hline & University & $39.4(39 / 99)$ & $64.1(25 / 39)$ & $59.6(59 / 99)$ \\
\hline & Government & $55.2(32 / 58)$ & $59.4(19 / 32)$ & $62.1(36 / 58)$ \\
\hline & International bilateral & $33.3(4 / 12)$ & $50.0(2 / 4)$ & $66.7(8 / 12)$ \\
\hline & Foundation & $27.3(3 / 11)$ & $66.7(2 / 3)$ & $90.9(10 / 11)$ \\
\hline & Multilateral & $0.0(0 / 5)$ & $0.0(0 / 0)$ & $100.0(5 / 5)$ \\
\hline \multirow[t]{5}{*}{ STEGH Care Setting } & Specialty hospital or national referral center & $45.5(43 / 94)$ & $65.1(28 / 43)$ & $63.8(60 / 94)$ \\
\hline & Primary level or district hospital & $47.3(44 / 93)$ & $70.5(31 / 44)$ & $65.6(61 / 93)$ \\
\hline & Community health care setting & $35.6(26 / 73)$ & $53.9(14 / 26)$ & $71.2(52 / 73)$ \\
\hline & Primary care clinic & $50.0(34 / 68)$ & $67.7(23 / 34)$ & $76.5(52 / 68)$ \\
\hline & Health center or dispensary & $43.2(16 / 37)$ & $56.3(9 / 16)$ & $67.6(25 / 37)$ \\
\hline \multirow[t]{3}{*}{ Returned to STEGH Location } & Non-returner (1 trip) & $52.6(10 / 19)$ & $60.0(6 / 10)$ & $73.7(14 / 19)$ \\
\hline & Returner (2-5 trips) & $40.5(47 / 116)$ & $53.2(25 / 47)$ & $65.5(76 / 116)$ \\
\hline & Frequent-returner (6+ trips) & $49.2(31 / 63)$ & $74.2(23 / 31)$ & $69.8(44 / 63)$ \\
\hline
\end{tabular}

settings. They also often fail to completely understand the cultural and structural aspects of the medical systems within these settings." (Resident MD, Obstetrics/Gynecology).

"[Visiting clinicians] need to consider urgency of situation and alternatives. Often the person from the HIC is not in the best position to judge this without understanding environment, culture, language. So such decisions should not be taken lightly." (Licensed MD, Family Medicine).

"For trainees, it is where to draw the line with what constitutes adequate supervision when allowing the resident to operate. For professionals in general it is when to say 'no' to an operation that may be outside of a surgeon's comfort level or one that is made riskier by the constraints of the environment." (Resident MD, General Surgery).

Respondents also provided details about factors that may contribute to being asked to perform or deciding to perform outside of scope.

"Local understanding of limited scope-the sense that just because I'm a doctor doesn't mean that I can fix everything or see every kind of patient." (Licensed MD, Pediatrics). 
"[When working abroad,] I sometimes performed beyond my scope of training in the U.S. but in accordance with what my scope of training would be expected to be in the country I was in." (Resident MD, Pediatrics).

\section{Reactions to and sentiments about POST}

Qualitative responses described a wide range of emotional responses related to POST, including anxiety, anger, frustration, and excitement. The majority of respondents who reported engaging in POST expressed negative emotions as a result (Table 4). When asked to describe their current feelings about past experiences, some who had engaged in POST cited persistent negative emotions, such as "guilt, frustration, remorse, discomfort, fear, and stress." Others reported acceptance of the outcome, describing POST as "the best thing that was possible" or "the right thing in the moment."

When asked to describe the most challenging situation in which respondents engaged in POST, responses reflected the theme of "a lack of alternatives," including perceived personnel shortage, lack of resources, and clinical urgency.

"[I was] asked to perform an arthrocentesis on a patient when this was not a skill I had previously performed. I did so due to a lack of alternate providers." (Licensed MD, Internal Medicine).

"Working outside your usual scope of practice [occurs] because there are limited specialists or referral options." (Licensed MD, General Surgery).

"I had to attempt to perform a pars plana vitrectomy as a last-ditch effort to save the eye, as our retina surgeon was back in the U.S. on furlough and the patient wasn't willing to go to the capital city four hours away... I was not successful in saving the vision. While I think the bad outcome of this was set regardless of whether I did something, did not do something, or whether I sent the patient to the capital city or not, I felt very out of my comfort zone." (Licensed MD, Ophthalmology).

Some clinicians described being asked to use knowledge or skills in which they had partial training at some point in time, typically in medical school, but that were not part of their current expertise.

"Sometimes I have to reach back to medical school training and improvisation to get some things done. I see and do a greater variety of clinical scenarios when overseas but still feel like I am relying on past training when I commit to treatment/intervention. Occasionally I have felt pressured to make clinical decisions that I felt underprepared to make-usually due to the combination of the patient scenario and lack of info/diagnostics that would be helpful." (Licensed MD, Pediatrics).

"As an internal medicine resident, I saw and cared for children... Both myself and the attending did not have training apart from medical school in pediatrics." (Resident MD, Internal Medicine).

Some respondents suggested that students participating in STEGH expect to perform outside their scope of training, and that opportunities to engage in POST are part of the strategy for recruiting volunteers and sustaining programs.

Table 4 Selected Examples of Health Professionals' Emotional Reactions and Sentiments Related to POST during STEGH

\begin{tabular}{|c|c|c|}
\hline Emotion & Illustrative Quote & Respondent \\
\hline Anxiety & "I was anxious. There seemed to be no easy answer of what was the best thing to do." & $\begin{array}{l}\text { MD Fellow, Internal Medicine and } \\
\text { Pediatrics }\end{array}$ \\
\hline Frustration & $\begin{array}{l}\text { "I felt overwhelmed by the responsibility, terrified I was going to give suboptimal care } \\
\text { that could result in death, and angry/frustrated that I was in the position of providing } \\
\text { care beyond my scope or not providing care to these infants." }\end{array}$ & $\begin{array}{l}\text { Licensed advanced practice provider } \\
\text { Obstetrics/Gynecology }\end{array}$ \\
\hline Discomfort & $\begin{array}{l}\text { "It is uncomfortable. You have years of training and are often looked to as the expert, } \\
\text { but in reality, you have not been training in such activities and do not have the skills } \\
\text { to complete such tasks. You don't want to stand by and do nothing, but at the same } \\
\text { time you don't want to do more harm than good. I am often left feeling incredibly } \\
\text { inadequate and inept." }\end{array}$ & MD Fellow, Pediatrics \\
\hline Remorse & $\begin{array}{l}\text { "If I didn't do something, the patient would have a worse outcome. Something was } \\
\text { better than nothing... I don't regret it, but I wish it ended differently, since the } \\
\text { patient died." }\end{array}$ & MD student \\
\hline Excitement & "Excited... Everybody should be exposed to such challenges especially in LMICs." & Licensed MD, Plastic Surgery \\
\hline Conflicted & $\begin{array}{l}\text { "Torn. On one hand, not appropriate. On the other hand, if I didn't do it, who would?... } \\
\text { [I felt] bad. It was unfair to the patients." }\end{array}$ & MD Fellow, Obstetrics/Gynecology \\
\hline
\end{tabular}


"[A challenge is] providing a meaningful experience for the students that will encourage them to speak positively about the program (to ensure continuation of the program) without subjecting the populations in the LMIC setting to undue harm. Often there is less concern in the general population of these areas for clear consent and patient self-advocacy, so pre-med students are often presented as higher ranking or more knowledgeable than they actually are." (Allopathic medical student).

The opportunity costs of POST were also noted, and some respondents postulated that efforts to address immediate clinical situations may compromise capacitybuilding and health systems strengthening.

"Too often professionals or trainees feel obligated to provide clinical care based on their own standards and cultural norms that are either out of proportion or not aligned with local customs and practices, misuse local resources, or [are] out of the realm of their scope of practice to feel good about themselves helping patients who are in need of care. Instead, their efforts, energy, and resources could be directed at improving the clinical skills and capacity of local infrastructure to provide the same level of care they wished was being done so many more could be helped within the confines of the local health system, according to cultural practices and prioritize the local resources appropriately." (MD Fellow, Pediatrics).

\section{Discussion}

Situations in which visitors may feel pressure or justification to perform beyond their scope have been identified as one of the major ethical dilemmas associated with STEGH $[12,16,23-27,29,30,33,37,42-44]$. POST is generally contradictory to professional guidelines, risks patient safety, and may violate national laws and regulations; understanding this phenomenon is of critical importance. Although POST has been described as a major ethical challenge in international health practice, previous research about POST in the context of STEGH is limited $[3,5,7,9,16,24,28,32,35-38]$. Despite calls to action for more intensive pre-departure ethics training and stronger partnerships for STEGH $[13,28,32,45,46]$, few studies have actually examined POST among the large population of health professionals and trainees participating in STEGH.

This study is the first to systematically characterize the prevalence of POST during STEGH and to elucidate the circumstances and emotional ramifications of POST. As such, our study offers important insights for interventions that might reduce inappropriate practices and, by extension, reduce unintended harms.

This study provides compelling new evidence that HIC health professionals and trainees participating in professional activities during STEGH are asked to and do perform outside their scope of training with high frequency. Nearly half of study participants reported being asked to perform beyond their scope and more than $60 \%$ of those respondents engaged in POST. Our results also highlight that POST is not merely an issue for clinicians, as one in four respondents involved in non-clinical activities during their STEGH were asked to perform clinical activities outside their training. POST is a challenge for everyone, no matter what type of host organization or practice site they select $[3,7,8,47]$. Findings from our study make apparent a need for expanded access to and uptake of high-quality education about POST, as well as professional guidelines for responding to requests, across the breadth of STEGH activities and participants.

Understanding why POST occurs is critical to designing interventions that will reduce its occurrence. Our respondents felt that POST was a common practice during STEGH, and its commonality may foster a sense of its normalcy. Respondents also identified a mismatch between hosts' expectations and visiting health professionals' training, suboptimal supervision, and inadequate preparation to decline POST as among the most important situational factors leading to POST. While emergencies and resource shortages cannot always be avoided, mismatched expectations can be addressed, supervision arranged, and management of ethical and moral challenges prepared for in advance. These may be more effective strategies for mitigating POST than attempting to modify beliefs about its appropriateness. Indeed, in our study population, such beliefs were not strongly associated with decisions about POST, one way or the other.

Finally, the emotionally and morally distressing dimensions of POST cannot be overlooked. The persistence of negative feelings about past experiences with POST underscores the need not only to prepare individuals to handle requests, but to debrief about those situations afterwards, with special consideration given to those who have been exposed to highly traumatic events.

This study has several limitations. First, North Americans were disproportionately represented, so the results primarily reflect the attitudes and experiences of individuals from North America. Second, by necessity our survey was developed de novo and did not include validated items. Third, the use of convenience and snowball sampling prevented a determination of the full number of potential participants who were contacted and the calculation of a response rate. Fourth, there is the possibility of response bias, skewing our sample towards those with experience involving POST. 
Fifth, for both the survey and open-ended items, it is possible that recall bias (e.g., respondents' remembering negative experiences over positive ones) and social desirability bias (e.g., respondents' reporting negative emotional experiences over positive ones because they believe that is what researchers want to hear) influenced our findings. Lastly, despite our efforts at minimizing the effect of the researchers' own subjective biases in the qualitative analysis through reflexivity, as for all qualitative studies, this subjectivity could have affected our findings.

In summary, our study participants have, cumulatively, decades of experience working in health settings with limited resources and partnering with international host organizations for STEGH. And yet, despite this extensive experience, one of the most basic ethical issues encountered during STEGH continues to elude straightforward solutions. Researchers in global health ethics have proposed several frameworks for navigating dilemmas that might arise during STEGH, including requests for POST $[3,7,9,24,32,34-36,38,48]$. We agree with existing recommendations that pre-departure training should be required; that expectations, scope of training, and necessary supervision should be established prior to starting STEGH; that activities should be undertaken with a commitment to local capacity-building; and that the burden of educating visitors about the local clinical, legal, and cultural environment should not fall disproportionately on the hosts. However, improved recommendations and frameworks that specifically address POST are still needed $[26,32,35,49]$. We also recognize that while we can create better models to aid in decision-making, the outcomes of ethically challenging situations can never be absolutely certain. The goal should be to close the gap between providing necessary care and doing unintentional harm.

\section{Conclusions}

Our study is one of the first to delve into the context and consequences of POST during STEGH, but it should not be the last. There is an urgent need for additional research on POST that explores these circumstances in greater detail, so that students, professionals, organizations, and partnerships are able to make informed decisions about creating, funding, and participating in these programs. We should prioritize the highest principles and aims of global health, emphasizing sustainability and safety. It is time for an honest reckoning with the challenges of POST.

\section{Supplementary information}

Supplementary information accompanies this paper at https://doi.org/10. 1186/s12992-019-0506-6.

Additional file 1. Qualtrics survey instrument.

\section{Abbreviations}

HIC: High-income countries; LMIC: Low- and middle-income countries; POST: Performing outside one's scope of training; STEGH: Short-term experiences in global health

\section{Acknowledgements}

The authors would like to thank the Consortium of Universities for Global Health (CUGH) Research and Education Committees, Mark Adler, Laurel Gabler, Adeolu llesanmi, and Phuoc Le.

\section{Authors' contributions}

AD-P, BDN, JE, MD, and NES contributed to the background research, study design, data collection, data analysis, data interpretation, and manuscript writing. $\mathrm{KHJ}$ and $\mathrm{CTE}$ contributed to the data analysis, data interpretation, and manuscript writing. JLG contributed to the background research, study design, data collection, and manuscript revisions. All authors read and approved the final manuscript.

\section{Authors' information}

ADP is an Assistant Professor in the Division of Hospital Medicine, Department of Medicine, and Director of the Center for Global Health Education at the Institute for Global Health, Feinberg School of Medicine, Northwestern University, Chicago, IL, USA.

JE is an Assistant Professor at the University of California San Francisco, and Executive Director of Child Family Health International, San Francisco, CA, USA. $\mathrm{MD}$ is an Associate Professor at the Center for Bioethics and Humanities and Division of General Internal Medicine, University of Colorado, Denver, CO, USA. CTE is an Associate Professor in the Department of Preventive Medicine, Feinberg School of Medicine, Northwestern University, Chicago, IL, USA. $\mathrm{KHJ}$ is a Professor in the Department of Global and Community Health George Mason University, Fairfax, VA, USA.

NES is a Program Assistant at the Institute for Global Health, Feinberg School of Medicine, Northwestern University, Chicago, IL, USA.

JLG is Associate Dean for Graduate Medical Education and an Associate Professor in the Department of Neurology and Department of Medical Education, Feinberg School of Medicine, Northwestern University, Chicago, IL, USA.

BDN is a pediatrician and global health faculty in the Divisions of Global Health and Neonatology, Department of Pediatrics, Massachusetts General Hospital, and Associate Professor at Harvard Medical School, Boston, MA, USA

\section{Funding}

None.

\section{Availability of data and materials}

The datasets used and analyzed during the current study are available from the corresponding author on reasonable request.

Ethics approval and consent to participate

The study protocol was approved by the institutional review board of Northwestern University (Protocol STU00205018), and all study participants provided voluntary, informed consent prior to participation.

\section{Consent for publication}

Not applicable.

\section{Competing interests}

Dr. DeCamp received an honorarium for work related to the American College of Physicians' position paper on short-term global health clinical experiences. The authors have no other declarations of interests.

\section{Author details}

${ }^{1}$ Division of Hospital Medicine, Departments of Medicine and Medical Education, Feinberg School of Medicine, Northwestern University, 51 E Huron St, Chicago, IL 60611, USA. Institute for Global Health, Feinberg School of Medicine, Northwestern University, 645 N Michigan Ave, Suite 1058, Chicago, IL 60611, USA. ${ }^{3}$ University of California San Francisco, 505 Parnassus Ave, San Francisco, CA 94143, USA. ${ }^{4}$ Child Family Health International, 400 29th St, Suite 508, Oakland, CA 94609, USA. ${ }^{5}$ Center for Bioethics and Humanities and Division of General Internal Medicine, University of Colorado, 13080 E. 19th Avenue, Aurora, Colorado 80045-2571, USA. ${ }^{6}$ Department of Preventive 
Medicine, Feinberg School of Medicine, Northwestern University, 680 N Lake Shore Dr, Chicago, IL 60611, USA. 'Department of Global and Community Health, George Mason University, 4400 University Dr, Fairfax, VA 22030, USA. ${ }^{8}$ Departments of Neurology, Pediatrics, and Medical Education, Feinberg School of Medicine, Northwestern University, 303 E Chicago Ave, Chicago, IL 60611, USA. ${ }^{9}$ Divisions of Global Health and Neonatology, Department of Pediatrics, Massachusetts General Hospital, 125 Nashua St, Boston, MA 02114 USA. ${ }^{10}$ Harvard Medical School, 25 Shattuck St, Boston, MA 02115, USA.

\section{Received: 19 June 2019 Accepted: 11 October 2019}

\section{Published online: 01 November 2019}

\section{References}

1. Adelman C, Schwartz B, Riskin E. Index of global philanthropy and remittances 2016. Washington: Center for Global Prosperity, Hudson Institute; 2016.

2. American Association of Medical Colleges. Medical school graduation questionnaire: 2018 all schools summary report. Washington: AAMC; 2018.

3. DeCamp M, Lehmann LS, Jaeel P, Horwitch C. Ethical obligations regarding short-term global health clinical experiences. Ann Intern Med. 2018;169:651-7.

4. Drain PK, Holmes KK, Skeff KM, Hall TL, Gardner P. Global health training and international clinical rotations during residency: current status, needs, and opportunities. Acad Med. 2009;84:320-5.

5. Jesus JE. Ethical challenges and considerations of short-term international medical initiatives: an excursion to Ghana as a case study. Ann Emerg Med. 2010:55:17-22.

6. Kerry VB, Walensky RP, Tsai AC, Bergmark RW, Bergmark BA, Rouse C, Bangsberg DR. US medical specialty global health training and the global burden of disease. J Glob Health. 2013;3:020406.

7. St Clair NE, Pitt MB, Bakeera-Kitaka S, McCall N, Lukolyo H, Arnold LD, et al. Global health: preparation for working in resource-limited settings. Pediatrics. 2017;140:e20163783.

8. Asgary $R$, Junck $E$. New trends of short-term humanitarian medical volunteerism: professional and ethical considerations. J Med Ethics. 2013;39:625-31.

9. Crump JA, Sugarman J. Working group on ethics guidelines for Global Health training (WEIGHT). Ethics and best practice guidelines for training experiences in global health. Am J Trop Med Hyg. 2010;83:1178-82.

10. Crump JA, Sugarman J. Guidelines for global health training. Health Aff. 2011;30:1215.

11. Lasker JN. Hoping to help: the promises and pitfalls of global health volunteering. Ithaca: ILR Press; 2016.

12. Lasker JN, Aldrink M, Balasubramaniam R, Caldron P, Compton B, Evert J, et al. Guidelines for responsible short-term global health activities: developing common principles. Glob Health. 2018;14:18.

13. Bozinoff N, Dorman KP, Kerr D, Roebbelen E, Rogers E, Hunter A, et al. Toward reciprocity: host supervisor perspectives on international medical electives. Med Educ. 2014;48:397-404.

14. Citrin DM. The anatomy of ephemeral healthcare: "health camps" and shortterm medical voluntourism in remote Nepal. Stud Nepali Hist Soc. 2010;15: 27-72.

15. Kraeker C, Chandler C. "We learn from them, they learn from us": global health experiences and host perceptions of visiting health care professionals. Acad Med. 2013;88:483-7.

16. Melby MK, Loh LC, Evert J, Prater C, Lin H, Khan OA. Beyond medical "missions" to impact-driven short-term experiences in global health (STEGHs): ethical principles to optimize community benefit and learner experience. Acad Med. 2016;91:633-8.

17. Montgomery LM. Short-term medical missions: enhancing or eroding health? Missiology. 1993;21:333-41.

18. Suchdev P, Ahrens K, Click E, Macklin L, Evangelista D, Graham E. A model for sustainable short-term international medical trips. Ambul Pediatr. 2007;7: 317-20.

19. Russ CM, Ganapathi L, Marangu D, Silverman M, Kija E, Bakeera-Kitaka S, Laving A. Perspectives of host faculty and trainees on international visiting faculty to paediatric academic departments in East Africa. BMJ Glob Health. 2016;1:e000097.

20. Wolfberg AJ. Volunteering overseas-lessons from surgical brigades. N Engl J Med. 2006:354:443-5.

21. Abedini NC, Gruppen LD, Kolars JC, Kumagai AK. Understanding the effects of short-term international service-learning trips on medical students. Acad Med. 2012;87:820-8.
22. Barnard D, Bui T, Chase J, Jones E, Loeliger S, Velji A, White MT. Ethical issues in global health education. In: Chase J, Evert J, editors. Global health training in graduate medical education: a guidebook. 2nd ed. San Francisco: Global Health Education Consortium; 2011. p. 25-43.

23. Creaton A. Embodying the three Rs in Fiji. N Engl J Med. 2016;375: 1820-1.

24. Elit L, Hunt M, Redwood-Campbell L, Ranford J, Adelson N, Schwartz L. Ethical issues encountered by medical students during international health electives. Med Educ. 2011;45:704-11.

25. Harrison J, Logar T, Le P, Glass M. What are the ethical issues facing globalhealth trainees working overseas? A multi-professional qualitative study. Healthcare. 2016:4:43.

26. Logar T, Le P, Harrison JD, Glass M. "First do no harm": teaching global health ethics to medical trainees through experiential learning. J Bioeth Inq. 2015;12:69-78.

27. Provenzano AM, Graber LK, Elansary M, Khoshnood K, Rastegar A, Barry M. Short-term global health research projects by US medical students: ethical challenges for partnerships. Am J Trop Med Hyg. 2010;83:211-4.

28. Schwartz L, Sinding C, Hunt M, Elit L, Redwood-Campbell L, Adelson N, et al. Ethics in humanitarian aid work: learning from the narratives of humanitarian health workers. AJOB Prim Res. 2010;1:45-54.

29. Crump JA. Ethical considerations for short-term experiences by trainees in global health. JAMA. 2008;300:1456-8.

30. DeCamp M. Scrutinizing global short-term medical outreach. Hast Cent Rep. 2007;37:21-3.

31. Ott BB, Olson RM. Ethical issues of medical missions: the clinicians' view. HEC Forum. 2011;23:105-13.

32. Hunt MR, Schwartz L, Fraser V. "How far do you go and where are the issues surrounding that?" Dilemmas at the boundaries of clinical competency in humanitarian health work. Prehosp Disaster Med. 2013;28:502-8.

33. Hunt MR, Sinding C, Schwartz L. Tragic choices in humanitarian health work J Clin Ethics. 2012;23:338-44.

34. Roche SD, Ketheeswaran P, Wirtz VJ. International short-term medical missions: a systematic review of recommended practices. Int J Public Health. 2017;62:31-42.

35. Sheather J, Shah T. Ethical dilemmas in medical humanitarian practice: cases for reflection from Médecins Sans Frontières. J Med Ethics. 2011; 37:162-5.

36. Banatvala N, Doyal L. Knowing when to say "no" on the student elective: students going on electives abroad need clinical guidelines. BMJ. 1998;316: 1404-5.

37. Petrosoniak A, McCarthy A, Varpio L. International health electives: thematic results of student and professional interviews. Med Educ. 2010;44:683-9.

38. Huish R. The ethical conundrum of international health electives in medical education. J Glob Citizenship Equity Educ. 2012;2:1-19.

39. WHO Guidelines on Hand Hygiene in Health Care. Appendix 1: Definitions of health-care settings and other related terms. Geneva: World Health Organization; 2009.

40. Doobay-Persaud A, Evert J, DeCamp M, Evans CT, Jacobsen KH, Sheneman NE, Goldstein JL, Nelson BD. Practising beyond one's scope while working abroad. Lancet Glob Health. 2019;7:8:e1009-10.

41. Saldaña J. The coding manual for qualitative researchers. SAGE: Los Angeles; 2013.

42. Loh LC, Chae SR, Heckman JE, Rhee DS. Ethical considerations of physician career involvement in global health work: a framework. J Bioeth Inq. 2015; 12:129-36.

43. McKinley DW, Williams SR, Norcini JJ, Anderson MB. International exchange programs and U.S. medical schools. Acad Med. 2008;83:S53-7.

44. Wall LL, Wilkinson J, Arrowsmith SD, Ojengbede O, Mabeya H. A code of ethics for the fistula surgeon. Int J Gynaecol Obstet. 2008;101:84-7.

45. Bozorgmehr K. Rethinking the "global" in global health: a dialectic approach. Glob Health. 2010;6:19.

46. Wikler D, Brock DW. Population-level bioethics: mapping a new agenda. In: Green RM, Donovan A, Jauss SA, editors. Global bioethics: issues of conscience for the twenty-first century. Oxford: Oxford University Press; 2008. p. 15-35.

47. Arya AN, Evert J. Global health experiential education: from theory to practice. Abingdon: Routledge; 2017. 
48. Loh LC, Cherniak W, Dreifuss BA, Dacso MM, Lin HC, Evert J. Short term global health experiences and local partnership models: a framework. Glob Health. 2015;11:50.

49. Lahey T. A proposed medical school curriculum to help students recognize and resolve ethical issues of global health outreach work. Acad Med. 2012; 87:210-5.

\section{Publisher's Note}

Springer Nature remains neutral with regard to jurisdictional claims in published maps and institutional affiliations.

Ready to submit your research? Choose BMC and benefit from:

- fast, convenient online submission

- thorough peer review by experienced researchers in your field

- rapid publication on acceptance

- support for research data, including large and complex data types

- gold Open Access which fosters wider collaboration and increased citations

- maximum visibility for your research: over $100 \mathrm{M}$ website views per year

At BMC, research is always in progress.

Learn more biomedcentral.com/submissions 